\title{
The DIP-approach: student-staff partnerships as a vital tool for learning developers and educators to develop academic [and digital] literacies
}

\author{
Alexandra J.F. Patel \\ University of Leicester, UK \\ Mark Van Der Enden \\ University of Leicester, UK \\ Patsy Clarke \\ Oxford Brookes University, UK \\ Frances Deepwell \\ University of Leicester, UK \\ Bethany Z. Cox \\ University of Leicester, UK \\ Phil Marston \\ University of Leicester, UK \\ Steve Rooney \\ University of Leicester, UK
}

\section{Abstract}

Student-staff partnerships can be used to support the development of contextualised digital learning and teaching practices. This can be done by shifting the focus from IT skills to addressing a priority in learning and teaching using a digital approach that is appropriate for that discipline. The development of a formal 'Digital Innovation Partnership' (DIP) scheme at the University of Leicester brings students' digital confidence, perspectives and motivation to enhance learning and teaching. It also recognises the valuable contribution and expertise of student and staff participants. This draws on the academic literacies work of Lea and Street $(1998 ; 2006)$ and digital literacies work of Sharpe and Beetham (2010) to appreciate that staff and students are developing social practices that are situated within a discipline and intertwined with social, cultural and political factors, power and identity. 
The reasons for the success of the scheme are explored here, with recommendations for how the model can be applied more generally to educational design to support students' academic literacies development.

Keywords: student - staff partnership; digital literacies; academic literacies; learning communities.

\section{Introduction}

The development of digital literacy is widely perceived to be important for citizenship (for example, the extensive work of the European Union DigComp 2.0 https://ec.europa.eu//rc/en/digcomp) and in higher education in the UK, JISC are at the forefront of considering Digital Capabilities (https://www.jisc.ac.uk/rd/projects/buildingdigital-capability). The University of Leicester has recently committed itself to the creation of a Digital Campus and underpinned this intention by the creation and implementation of a new Digital Strategy. The strategy provides a framework for the institution (in all its facets) to raise its digital profile and a number of initiatives have already been deployed in this respect. The notion of a Digital Campus is not restricted, however, to service initiatives but equally aims to raise the bar in terms of developing and implementing digital practices in the realm of learning and teaching.

In order to support staff in raising their digital practice and develop innovative digital approaches to learning and teaching, the Digital Strategy has developed in collaboration with the Leicester Learning Institute a new project, the Digital Innovation Partnership (abbreviated to DIP). DIP is a student - staff partnership scheme designed to raise the digital literacy/capability of students and staff through initiating, supporting and implementing the development of locally meaningful digital enhancement projects which address current pedagogical challenges and/or opportunities. DIP is designed to support students and staff in collaborating to improve the learning and teaching experience by jointly identifying elements within the curriculum which could benefit from incorporating new or existing digital technologies. DIP is unique within the University of Leicester because it provides a formal platform and mechanism for students to share their perspectives and work with staff as partners to implement and deliver jointly developed projects. 
In this paper we will present DIP as a recently initiated project and outline its aims, approach and structure in some detail. We will also briefly explore some of the projects currently underway and report on the impressions obtained from the ongoing evaluation of the scheme. Finally, this paper aims to draw attention to the role of the learning developer in supporting academic literacies and partnership working across the curriculum amongst both students and staff. The DIP scheme is presented as a potential model for learning developers interested in exploring and supporting academic literacies in curricular settings through the medium of student - staff partnership.

\subsection{Digital literacies as academic literacies}

The Academic Literacies approach that we subscribe to has been defined by Lea and Street (1998, p.159) as the following:

[The Academic literacies approach]...views student writing and learning as issues at the level of epistemology and identities rather than skill or socialisation. [It] views the institutions in which academic practices take place as constituted in, and as sites of, discourse and power. It sees the literacy demands of the curriculum as involving a variety of communicative practices, including genres, fields and disciplines. From the student point of view a dominant feature of academic literacy practices is the requirement to switch practices between one setting and another, to deploy a repertoire of linguistic practices appropriate to each setting, and to handle the social meanings and identities that each evokes.

Lea and Street (1998; 2006) have argued that educators in higher education need to move beyond an idea of study skills that are generic, isolated and transferable, and instead use an academic literacies approach. This means we must appreciate that we are dealing with contextualised practices that include disciplinary rules and conventions around academic language, accepted methodologies, and how a discipline constructs, understands and communicates knowledge. In addition to this, Lea and Street (1998; 2006) extend our understanding of 'ways of doing' and 'ways of thinking' to realise that these practices are situated within social, cultural and political contexts. When helping learners understand, adopt and even challenge these academic ways of thinking and doing, we must encourage them to consider aspects such as social interactions, diversity, power structures and hierarchy, and hidden political agendas, for example. The same can be argued for 'digital 
literacy'. Walker and Patel (2018) suggest that digital literacies are an extension of academic literacies for several reasons - first, much of what we do in higher education is mediated by digital technologies to varying extents - whether it involves using research software to create knowledge; or accessing, analysing, and evaluating digital texts and other sources; or communicating through electronic texts, presentations, or web resources. Second, the digital 'ways of thinking' and 'ways of doing', like academic practices, are above all social practices - again meaning these are contextualised disciplinary practices that are bound up with power and identity (Walker and Patel, 2018).

The arguments of Lea and Street $(1998 ; 2006)$ in many ways align well with the work by Sharpe and Beetham (2010) and Bennett (2014) around becoming digital practitioners (for a more detailed discussion see Walker and Patel, 2018). All suggest that to view skills, whether 'study skills' or 'IT skills', as discrete, generic, isolated and easily transferable from one context to another, is unhelpful. For example, an educator may have the IT skills to operate MS PowerPoint but that alone does not make them a good teacher - instead, they must make informed, critical choices about how to use PowerPoint in a meaningful way for their particular purpose and audience.

When considering how people become digitally capable, Sharpe and Beetham (2010) suggest that learners require or develop the following areas, and these can be linked to the conceptualisation of academic literacies (see Figure 1):

Access - to time, support, resources, hardware, software, networks. We must acknowledge that access to these resources can be dependent on power dynamics, organisational structures, and many other socio-cultural and political factors. For example, IT departments may traditionally be gate-keepers to installation and licencing of both hardware and software, without which an individual cannot develop associated ways of working.

Skills - the ability to operate software/hardware.

Practices - an understanding of how those skills can be used in meaningful, contextualised ways of working within a discipline or social context. Here, digital practices align well with Lea and Street's (2006) emphasis on academic literacies being situated social practices. 
Digital attributes and identity - Ultimately an individual starts to see 'digital' as part of their identity and repertoire, to the extent of becoming post-digital and no longer seeing digital as something strange or 'other'. It also means being critical about choosing the appropriate tool for a task, whether digital or non-digital. The development of a digital identity speaks to Lea and Street's $(1998 ; 2006)$ notion of developing an academic identity. We can further draw on their work to consider the interplay of different identities, political agendas and discourses around digital - something that has been called for in the development of digital citizenship. Brown (2017) argues that if we truly wish to develop 'digital citizens' then we should prepare them to challenge and reshape the unjust societies we live in, as opposed to 'fitting' in with them.

Adopting this way of thinking, therefore, requires us to structure our learning development programmes to move beyond study skills and IT-skills, and instead develop social practices that are situated within a context and discipline. We propose that student-staff partnerships are one effective approach towards achieving this.
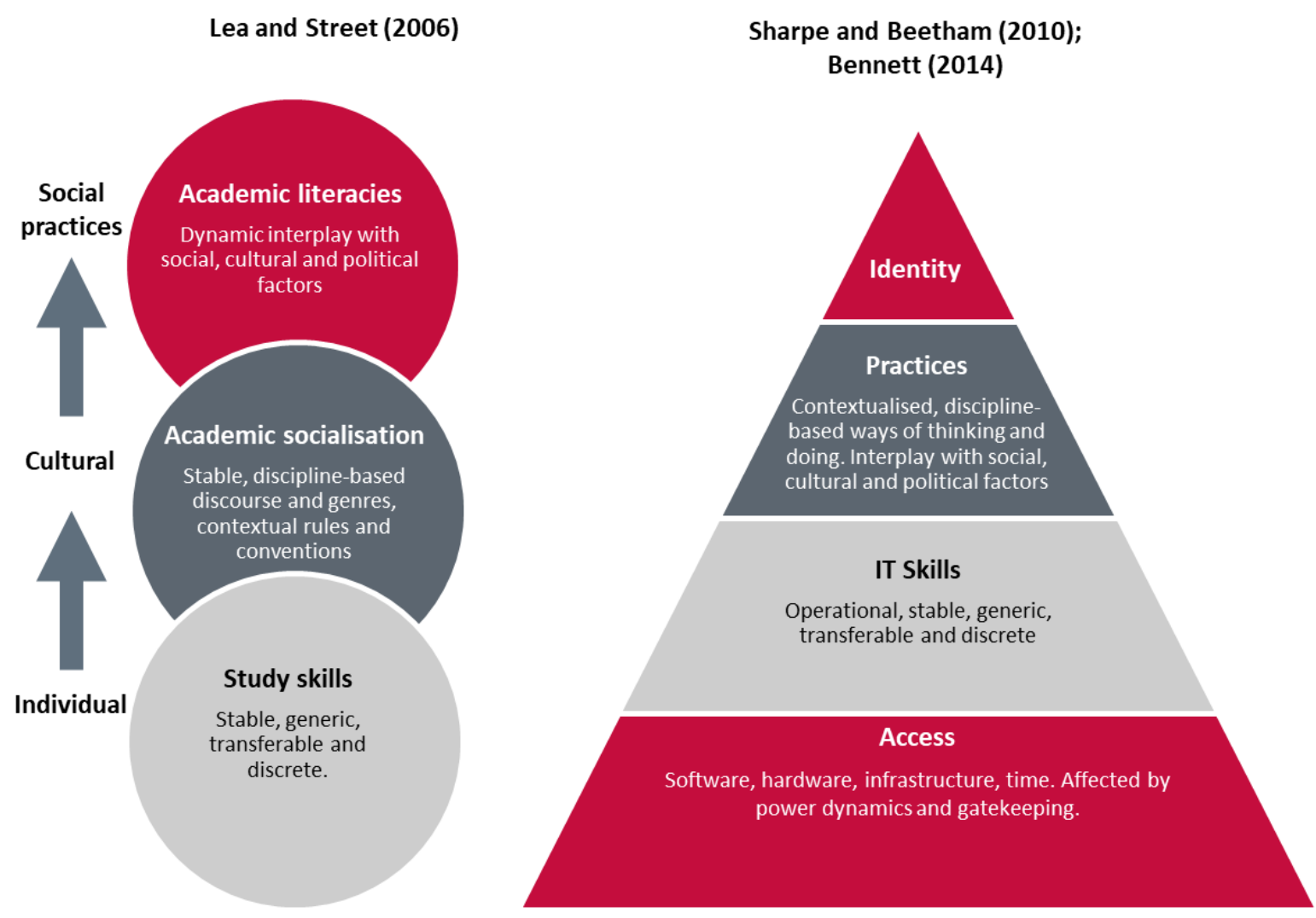

Figure 1. The relationship between academic literacies (Lea and Street, 1998; 2006) and digital literacies (Sharpe and Beetham, 2010; Bennett, 2014). Reproduced from Walker and Patel (2018). 


\subsection{Role of student-staff partnerships in literacies development}

As learning developers we are convinced of the benefits of engaging with students as partners and see the creation of opportunities for students to become more actively involved in developing their own teaching and learning environment as a core part of our job. The potential benefits that this can confer upon student participants are tremendously powerful and can range, for example, from increased student engagement with their learning, to the creation of a sense of institutional belonging and a community of practice, to enhanced employability skills (see Healey et al., 2014; Bovill et al., 2009; Bovill and Bulley, 2011; Evans et al., 2015; Freeman et al., 2014; Marquis et al., 2016). A core benefit of involving students as partners in learning and teaching is the sharing of different perspectives that this enables. As learners, and as participants in the educational experience, students have potentially a very different perspective from staff. Incorporating their perspectives, instead of trying to second guess what students might want or need, proves time and again to be insightful and constructive, and there are various ways in which this can be accomplished.

The HEA (now also part of AdvanceHE) framework for partnership provides a good starting point for an overview of the areas in learning and teaching in which partnership working can take place (HEA, 2015). Students can be engaged as partners in, for example, curriculum transformation, co-creation of assessment practices; pedagogical consultancy; peer assisted learning; authentic research experiences; or pedagogical research.

One of the primary benefits associated with engaging students in this manner, not mentioned so far but particularly relevant for learning developers, is the increased understanding of academic practices and their own learning that participating students experience. Helping to co-create assessment criteria provides students, for example, with much greater insights into what these are and how to go about using them (Deeley and Bovill, 2017; Healey et al., 2014). The same can be said, for example, for students acting as peer assisted learning leaders (for PAL benefits see Green, 2011). Student - staff partnership is, thus, one way in which students can be supported in their learning, and DIP provides a model for doing so and one which might be of interest to other learning developers. 
Student-staff partnership working equally may act as a counter to the current consumerist view of higher education. Students are encouraged and enabled to position themselves not as passive recipients of their educational experience but instead are invited to actively collaborate with staff in shaping their learning and teaching environment (Healey et al., 2014). Working with students as partners can create learning communities and facilitate the development of an inspiring and motivating environment for both staff and students. There is evidence from recent research literature (Chilvers, 2016) that such an environment may have the potential to make a difference with regards to addressing student transition into highly contextualised and discipline-specific academic literacies.

\subsection{DIP aims and structure}

The overall aim of the Digital Innovation Partnership (DIP) scheme is to enhance the student learning experience through the development of digital learning and teaching practices. The academic literacies perspective advocates that, instead of a focus on IT skills development, we should instead emphasise that these are social practices, situated within a disciplinary context, and bound-up with social, cultural and political issues (Lea and Jones, 2011). This translates into the following key DIP objectives:

- The establishment of a supportive and sustainable model of staff and student development of digital literacies in relation to teaching and learning.

- Involving students as active partners with staff in the design, development and/or delivery of teaching resources, activities and approaches, by drawing on their experience, perspectives and motivation.

- Sharing and recognising good practice and innovation in digital approaches to teaching and learning, in a way that is meaningful and beneficial to staff and students.

Inspired initially by the Oxford Brookes InStepp programme (https://www.brookes.ac.uk/instepp/), the DIP has a tripartite structure (Figure 2) made up of a member of teaching staff motivated to develop a digital teaching practice and requiring support (Digital Innovator), a student who has confidence, experience or ideas around digital tools and learning in a digital environment (Digital Associate), and a member of staff who has expertise in implementing change in digital practices in their discipline (Digital Advocate). The member of teaching staff and student work together on a small-scale, 
achievable, project of around 20 hours contribution each. They are supported and guided by the (digitally) more experienced member of staff (the Digital Advocate) who serves as a mentor to the team.

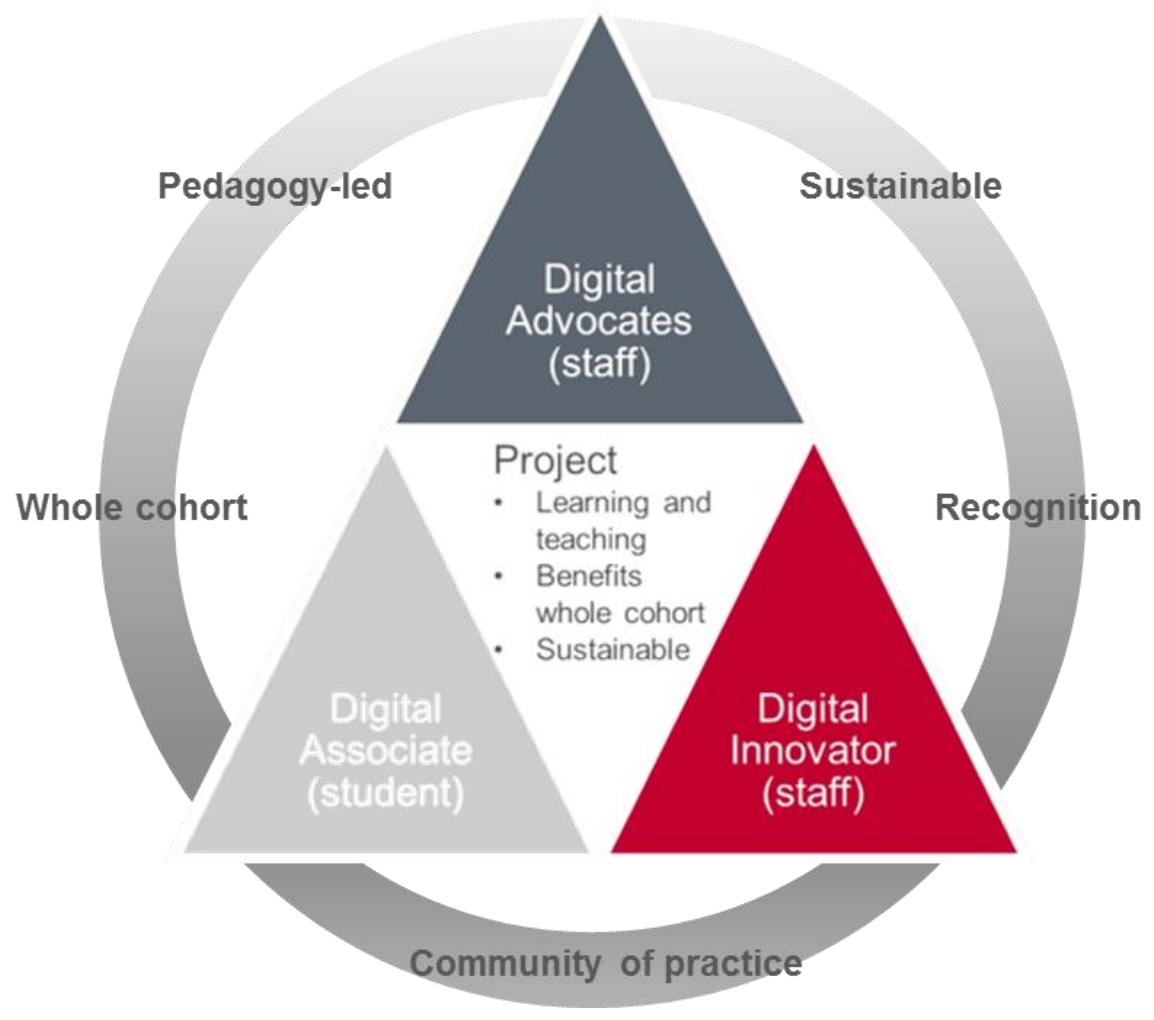

Figure 2. The Digital Innovation Partnership is a student-staff collaboration around a small-scale project to implement a meaningful digital learning and teaching practice. Projects must be led by pedagogy, impact an entire class or cohort; and be sustainable. The DIP scheme aims to recognise the good practice and share it through learning communities.

Each project must aim to enhance the learning experiences for a cohort of students, be informed by a pedagogic need and rationale as opposed to using technology for its own sake, and be sustainable for implementation in following years, for example, by using or integrating with institutionally supported software and technology.

In order to recognise and reward student participation, students accepted on to the scheme receive an award of $£ 200$ and an official Leicester Learning Institute certificate. Undergraduate students also have their involvement recorded under extracurricular activities on their HEAR transcript (Higher Education Achievement Report). Students and 
staff also receive a digital credential which gives further detail about their projects and links to supporting online evidence. More generally the scheme recognises student and staff participation by providing ample opportunity for projects to showcase their work (e.g. via conference presentation, seminars, website promotion, etc.).

\section{Methodology}

\subsection{The Digital Innovation Partnership approach - support, resources, timeline}

DIP was launched in the $2017 / 18$ academic year. Funding was provided in the first year as a pilot by the University of Leicester Digital Strategy and IT Services, with staff resource and expertise provided by the Leicester Learning Institute. We aimed to recruit 30 Digital Innovation Partnership teams, ten in each of the university's three colleges. Staff and students were recruited through a multipronged advertising campaign which involved pushing the initiative out via the usual e-mail channels, fly-posting in departments, liaising with directors of learning and teaching, and pedagogic research groups. Students and staff were invited to complete an online competitive application process (via the DIP website) in which they outline areas of (digital) interest, which were then used to pair up students and staff from the same disciplines with similar aims.

We required all teams to take part in a Planning Session, although we had to be flexible to accommodate availability. The Planning Session approach was developed in consultation with Leicester Learning Institute's (LLI) curriculum designers and was effective in focusing participating teams on the educational outcomes of their work, making sure that the key parameters of DIP were observed. The planning sessions also provided an opportunity for the DIP teams to present their ideas and receive feedback from key stakeholders and experts, and other teams in a 'Dragons Den' format. Furthermore, ethical approval was gained for a small range of standard evaluation approaches for teaching in order to facilitate later publication should partnerships so wish.

The scheme is flexible in its approach and works around student and staff commitments, whilst following an overall structure. This involves the planning session in which we scope out the projects; individualised follow-up meetings to provide further support and facilitate project progress; project teams are required to evaluate and present their work at the annual Leicester Learning and Teaching conference and to submit a final report (in the 
form of a poster). Partnerships are invited to attend an Evaluation Session based on Theory of Change (for more information see http://www.theoryofchange.org/what-istheory-of-change/; Anderson, 2012) to provide concise guidance around educational research approaches.

In order to further support the DIP teams, LLI supporting staff have created a number of resources available for use. A Blackboard test site which is intended to host tools, resources, guidance and, importantly, to create a safe space that students and teaching staff can use to develop digital resources without breaching GDPR (General Data Protection Regulation). Small sums of funding are also available to project members to cover travel to conferences or purchase of additional equipment.

\subsection{Evaluation methodology}

In our educational evaluation of the scheme, we deployed a simplified Theory of Change approach (resource available at: www.dip.le.ac.uk). We refined our long-term goal of the project as being the enhanced learning experience for students, and that this would be enacted through the following short-term goals, along with their measures/indicators:

- Successful collaboration between staff and students measured by individual interviews;

- Development of contextualised digital practices, measured by analysis of project themes and evaluation of pedagogic rationale;

- Development of digital confidence and identity, measured by individual interviews;

- Evaluation of individual projects, measured by project poster-reports;

- Recognition, sharing of good practice and development of learning communities, measured by individual interviews and analysis of how participants have made use of or shared this experience.

One hour structured interviews and focus groups were designed using social research principles (Cronin, 2008; Krueger and Casey, 2000; Wilkinson, 2008), with audio recordings transcribed and interpreted through thematic analysis (Braun and Clarke, 2006). Partnerships were required to submit a report in poster format and to evaluate the impact of their digital practice on the learning of students. Ethical approval was granted by the University of Leicester Ethics Sub-Committee for Criminology and School of Education. 


\section{Results and discussion}

Twenty-three out of a target of 30 projects have completed, or are on track to be implemented in Semester 1 of the current academic year. The projects span departments in the Colleges of Science and Engineering, Social Sciences, Arts and Humanities; and Life Sciences at the University of Leicester.

\subsection{Development of contextualised digital teaching and learning practices}

True to the aims of the scheme and its intention to foster contextualised development, the interviews reveal that staff and students have gone beyond learning IT skills and have indeed developed meaningful, contextualised digital practices that have been led by pedagogy and focused on a specific issue that will enhance the learning experience of students in those subject areas as shown by the project descriptions below. Some who were digitally savvy to start with reported having improved in some respects, for example, now knowing more about how to embed digital in teaching and learning. An advocate described an increase in digital confidence and competency beyond already known technologies and having become more familiar with aspects of teaching with technology. A student Associate with good digital skills now considers he understands better how to integrate that into a course and was able to expose other students to new technology. A student Associate benefited by expanding his knowledge about digital options that helped his own revision and gave him the opportunity to think about how to use more digital ways in his life.

The Planning Session was identified by participants as honing the partnerships to identity interventions that were specific to the disciplinary area, thus aiming at enhancing the student learning experience, instead of being technology-driven. This can be seen in the diversity and educational aim of the projects, grouped by emerging theme:

Use of virtual reality to help student transition to learning in a new environment: DIP teams from the School of Business and the School of Medicine used virtual reality to create a 360 degree Virtual Reality (VR) experience of campus and a medical-ward round. Both aimed to help students to transition as part of a package around studying at university, and to explore the challenges of learning in a clinical setting. 
Use of interactive tutorials to promote higher level thinking: DIP teams from the Medical School, Biological Sciences and Chemistry have been using a range of approaches to develop interactive, story-board, decision-based e-tutorials on topics such as the identification of microbiological epidemic; metabolism biochemical pathways, medical diagnosis and clinical reasoning; and safety in chemistry labs, respectively. Common to all projects is the emphasis on creating enquiry-based learning experiences where learners are immersed in real-world scenarios.

Video resource creation to capture and share information: DIP teams from Biological Sciences, Physiotherapy and Chemistry have been exploring the production and use of video to communicate information about plant identification on field trips, transition to University and building molecular models in a flipped classroom format.

\section{Collaboration, communication and participation to enhance learning experience:} DIP teams from Biological Sciences, Engineering and Physics have been improving student interaction in and around lectures using a range of approaches such as audiencevoting systems, online discussion forums, and interaction within virtual learning environment.

Use of learning Apps by students: A DIP team from Physiotherapy engaged students in a review process for learning apps using the virtual learning environment.

Electronic submission and feedback: DIP teams from Mathematics evaluated a range of electronic-submission and electronic-marking approaches for mathematical solutions. Teams from Criminology trialled audio-feedback within the Virtual Learning Environment and asynchronous audio discussions around assignments.

\subsection{Importance of student-staff partnerships}

'A huge level of respect between all the partners' (Advocate)

The evaluative interviews conducted have provided some insights into how the participants experienced working in partnership. The relationships between partners were diverse, with some student Associates being given a brief and told to 'get on with it', and in others all partners sharing in the ideas, decision-making and implementation. However, even where 
main decisions were taken by the staff member as an Advocate or Innovator, the student Associate had an active and significant role in checking whether the process and development was suitable and engaging for students and giving feedback.

Several student Associates commented that they valued the opportunity to work on the projects, for the opportunity to 'make a difference', learn new skills, or work with staff in a different way:

[It was]...valuable to encounter lecturers who I saw as authority figures in a more equal and collaborative way. (Student Associate)

...the most redeeming moment was when we were in the poster session, ... when we were talking to other people and when she said, 'oh she did most of the work', so I liked it that my work was recognised, not actually when I received 50 pounds before. (Student Associate)

Student Associates' input was also valued by Innovators in the projects for several reasons. First, they provided different views and student perspectives on learning, making materials more comprehensive in terms of language and were able to provide information on other departments' tools through friendship networks. One Innovator appreciated how a student Associate led her to new digital competencies, as well as helping to broaden out the project goals to be more generalisable than originally envisaged:

Just to have another set of eyes on the idea and a younger set of eyes that are much more familiar with these systems and also thinking in a different perspective to perhaps from you. But also having the link in through her to all the other students. (Innovator)

Just switching the relationship and allowing them to be helping and supporting me, rather than the other way around, and having a slightly different relationship with the student is good. And I valued the knowledge about the digital world coming through as well. But from this I learnt how to take a step back and not be the teacher for a bit, and actually let them learn and guide their learning. (Innovator) 
Second, student Associates, due to the selection process, had more familiarity with technology and provided digital skills. Third and last, student involvement 'enhanced the project'. Most Innovators commented on the inspiring ideas and different perspectives that students brought with them, and how it led to gathering other view points from a larger number of students. One Innovator went as far as suggesting that 'no digital resource should be designed without student involvement'.

It is also acknowledged that some partnerships, however, were less successful due to factors such as concurrent industrial action in the Spring of 2018; prioritisation of exams or departmental commitments over this project; differing interests of staff members and students, and lack of agency of staff-member or student to implement the idea within their own setting.

\subsection{Importance of recognition, sharing good practice and learning communities}

Creating opportunities for staff and students to share their good practice is reported as one of the most successful aspects to the scheme. During the evaluative interviews, several Innovators and Advocates spoke of the value of opportunities to showcase their work, to present posters, participate in conferences and learning and teaching events, and produce publications, both internally and externally to the university. For example, two teams from Chemistry presented separately at the Variety in Chemistry Education / Physics Higher Education Conference 2018, and a team from the School of Medicine presented at the Swansea University VR/AR Conference 2018. We intend to work with DIP 'alumni' to develop a learning community and further develop them as 'experts' in a particular digital teaching practice, and inspire others to consider digital approaches within their teaching. Some partners were keen to have more opportunities to present their work, particularly at a departmental level. Staff have reported using this experience as evidence of continuing professional development as originally intended, providing substance for applications for Fellowship or Senior Fellowship of the Higher Education Academy; University Distinguished Fellowship Award; for job applications; for Personal Development Discussions; and for their CV for promotion. The scheme itself, and key individuals in the team, have received recognition through a University award of Discovering Excellence. 


\section{Conclusion}

In conclusion, the scheme and the approach to digital literacies development that it represents, have led to significant enhancements to current practices. The scheme provides another mechanism that learning developers, in partnership with other educational colleagues, can use to support the development of meaningful and contextualised digital learning and teaching practices. The highlight features of the DIP that can be transferred to other contexts and other topics are:

- The use of group Planning Sessions that focus on Educational Design and pedagogy within a disciplinary context instead of being led by technology.

- Student-staff partnerships that, in addition to bringing a critical student perspective on learning in a digital environment, also encourage the consideration of broader issues, 'enhance' the project, and bring digital confidence and skills.

- Opportunities for partnerships to share their work with colleagues supports the development of learning communities that can inspire members and provide peer support and expertise.

- Recognition of good practice through opportunities to present and publish, nominations for Awards, and a certification.

Our Open Educational Access resources are available on webpages: www.dip.le.ac.uk

\section{Acknowledgements}

We would like to thank the DIP teams who worked on projects within this scheme and took part in its evaluation - it has been an inspiring journey for all of us. More information about them and their projects can be found at www.dip.le.ac.uk. 


\section{References}

Anderson, A.A. (2012) The community builder's approach to theory of change: a practical guide to theory development. Available at:

http://www.mspguide.org/sites/default/files/resource/aspen institute the community builders guide to theory of change.pdf (Accessed: 7 October 2018).

Bennett, L. (2014) 'Learning from the early adopters: developing the digital practitioner', Research in Learning Technology, 22, pp. 1-13 [Online]. Available at: https://doi.org/10.3402/rlt.v22.21453 (Accessed: 7 October 2018).

Bovill, C., Morss, K. and Bulley, C. (2009) 'Should students participate in curriculum design? Discussion arising from a first year curriculum design project and a literature review', Pedagogic Research in Maximizing Education, 3(2), pp. 17-26.

Bovill, C. and Bulley, C.J. (2011) 'A model of active student participation in curriculum design: exploring desirability and possibility', in Rust, C. (ed.) Improving student learning (18). Global theories and local practices: institutional, disciplinary and cultural variations. Oxford: The Oxford Centre for Staff and Learning Development, pp176- 188.

Braun, V. and Clarke, V. (2006) 'Using thematic analysis in psychology', Qualitative Research in Psychology, 3(2), pp. 77-101.

Brown, M. (May, 2017) Exploring the underbelly of digital literacies. OEB insights: midsummit, opinions. Available at: https://oeb-insights.com/exploring-theunderbelly-of-digital-literacies/ (Accessed: 7 October 2018).

Chilvers, L. (2016) 'Communities of practice for international students: an exploration of the role of PASS in supporting transition and learning in higher education', Journal of Learning Development in Higher Education, Special Edition: Academic Peer Learning (Part 2), April, pp. 1-25. 
Cronin, A. (2008) 'Focus groups', in Gilbert, N. (ed.) Researching social life. $3^{\text {rd }}$ edn. London: Sage, pp. 226-244.

Deeley, S.J. and Bovill, C. (2017) 'Staff student partnership in assessment: enhancing assessment literacy through democratic practices', Assessment \& Evaluation in Higher Education, 42(3), pp. 463-477.

Evans, C., Muijs, D. and Tomlinson, M. (2015) Engaged student learning: high-impact strategies to enhance student achievement. York: HE Academy.

Freeman, F., Millard, L., Brand, S. and Chapman, P. (2014) 'Student academic partners: student employment for collaborative learning and teaching development, Innovations in Education and Teaching International, 51(3), pp. 233-243.

Green, P.A (2011) Literature review of Peer Assisted Learning (PAL). National HE STEM.

Healey, M., Flint, A. and Harrington, K. (2014) Engagement through partnership: students as partners in learning and teaching in higher education. York: Higher Education Academy.

Higher Education Academy (2015) Framework for student engagement through partnership. York: HE Academy.

Krueger, R. and Casey, M.A. (2000) Focus groups: a practical guide for applied research. $3^{\text {rd }}$ edn. London: Sage.

Lea, M. and Jones, S. (2011) 'Digital literacies in higher education: exploring textual and technological practice', Studies in Higher Education, 36(4), pp. 377-393.

Lea, M. and Street, B. (1998) 'Student writing in higher education: an academic literacies approach', Studies in Higher Education, 23(2), pp. 157-172 [Online]. Available at: https://doi.org/10.1080/03075079812331380364 (Accessed: 7 October 2018). 
Lea, M. and Street, B. (2006) 'The 'Academic Literacies' Model: theory and applications', Theory into Practice, 45(4), pp. 346-351 [Online]. Available at: https://doi.org/10.1207/s15430421tip4504 11 (Accessed: 7 October 2018).

Marquis, E., Puri, V., Wan, S., Ahmad, A., Goff, L., Knorr, K., Vassileva, I. and Woo, J. (2016) 'Navigating the threshold of student-staff partnerships: a case study from an Ontario teaching and learning institute', The International Journal for Academic Development, 21(1), pp. 4-15.

Sharpe, R. and Beetham, H. (2010) 'Understanding students' uses of technology for learning: towards creative appropriation', in Sharpe, R.B., Beetham, H. and De Freitas, S. (eds.) Rethinking learning for a digital age: how learners are shaping their own experiences. London, England and New York, NY, Routledge, pp. 85-99.

Walker, S. and Patel, A.J.F. (2018) 'More than skills: what can approaches to digital literacies learn from academic literacies?', Journal of Learning and Teaching in Higher Education, 1(1), pp. 93-100 [Online]. Available at:

https://www108.lamp.le.ac.uk/ojs1/index.php/jlthe/article/view/856/2535 (Accessed: 7 October 2018).

Wilkinson, S. (2008) 'Focus groups', in Smith, J.A. (ed.) Qualitative psychology: a practical guide to research methods. London: Sage, pp. 186-206.

\section{Author details}

Dr Alexandra Patel combines a learning development perspective with her role as an Educational Developer at Leicester Learning Institute, University of Leicester. She is particularly interested in student-staff partnerships, academic and digital literacies, and applying these ideas to help staff and students develop in ways that are personally meaningful.

Dr Mark van der Enden is the Project Officer Student - Staff Partnerships at the Leicester Learning Institute at the University of Leicester. He is particularly interested in and passionate about collaborating with students (as genuine partners) in developing the 
learning and teaching environment, and creating institutional learning communities in which students and staff are empowered and enabled to benefit from each other's expertise and perspectives. Mark is involved in various 'students as partners' initiatives at the University of Leicester and additionally supports the learning development team in supporting student learning and academic literacies development.

Patsy Clarke spent four years as an Educational Developer in the Oxford Centre for Staff and Learning Development at Oxford Brookes University, where she supported a number of research projects including an Appreciative Inquiry for the JISC-funded Users and Innovation Research Programme. Since retirement, Patsy works as a Certified Platinum NVivo trainer and independent qualitative researcher in diverse fields including international development, HIV-AIDs, technology in education, professional development and creative methodologies.

Dr Frances Deepwell is Director of the Leicester Learning Institute at the University of Leicester. Her main interests lie in the areas of sustainable educational innovation and its evaluation, and how this contributes to continuing professional development in learning and teaching beyond initial training. She is Principal Fellow of the Higher Education Academy and Senior Fellow of the Staff and Educational Development Association, and founding Editor of the online Journal of Learning and Teaching in Higher Education.

Bethany Cox is a Digital Strategy Intern, part of the IT Services Department at the University of Leicester. She is currently working with the Leicester Learning Institute and Library, supporting the implementation of two innovative projects as part of the development of the university's Digital Campus.

Phil Marston is an Educational Development Adviser currently specialising in Assessment and Feedback. He has a particular interest in collaborative and peer supported learning. Phil also has extensive experience as a Technology-enhanced Learning Adviser, specialising in innovative uses of mobile technologies, game-based learning and Contemplative Pedagogy.

Steve Rooney is Head of Learning Development at the University of Leicester (UK). His particular focus is on working with academics and students to devise integrated, curriculum-level support for the development of academic literacies. 